\title{
Os tradutores, esses fazedores de cultura
} Alexandra Lopes

\author{
Thomas Bernhard, $O$ fazedor de teatro, \\ tradução de José A. Palma Caetano, Lisboa, \\ Assírio \&t Alvim, 2004, 143 pp.
}

1. Os fazedores de teatro: Bernhard, Bruscon e a irredutibilidade austríaca

0 actor acende a boca. Depois, os cabelos,

Finge as suas caras nas poças interiores.

Ninguém ama tão desalmadamente como o actor...

Herberto Helder

Em 0 fazedor de teatro (1984), Thomas Bernhard (1931-1989) autoparodia-se, num texto que apresenta um programa estético próximo do seu e um actor tão desalmado e misantrópico quanto ineficaz. A peça parte, aliás, de um episódio real ocorrido em 1972 em torno de um projecto artístico que ficaria conhecido como "poética da escuridão" (Poetik der Finsternis). Aquando da estreia de Der Ignorant und der Wahnsinnige no Festival de Salzburgo, Bernhard insistira em que se apagassem as luzes de emergência, para que a sala do Landestheater ficasse totalmente às escuras. Não conseguiu, porém, persuadir o corpo de bombeiros e obter a devida autorização (Höller 1993: 126), facto que gerou uma das muitas controvérsias a que Bernhard viria a estar associado ao longo da sua vida de escritor e que culminariam na vontade expressa de que as suas obras não fossem divulgadas nem representadas na Áustria

Em O fazedor de teatro, o actor Bruscon, protagonista indiscutivel e voz (quase) única na peça, confronta-se, num registo tragicómico, com idêntica dificuldade num cenário mais modesto - Utzbach substitui Salzburgo -,

${ }^{1}$ Utilizaremos aqui a terminologia proposta por Aguiar e Silva, segundo a qual o texto dramático se actualiza como texto teatral "através de um complexo processo de transcodificação intersemiótica" (Aguiar e

Silva 1983: 614). De

salientar que esta

transcodificação pode ser desde logo entendida como um processo de tradução (vide Jakobson 2000: 114). acentuando a redução sociogeográfica quer a comicidade da situação, quer a tacanhez da "cloaca no abcesso da Europa" (p. 54) que seria a Áustria.

Se a reflexão quase obsessiva, e sempre crítica, sobre a Áustria e os austríacos tornaram Bernhard, em diversos momentos, persona non grata no seu próprio país, ela não deixou também de enformar toda a sua escrita - a dramática como a narrativa -, fazendo dele, talvez de modo paradoxal um escritor enraizadamente "austríaco". Acresce que, ao temário, se junta uma relação indagadora e desestabilizadora com a língua alemã, que se inscreve, ainda que de modo ínvio, na tradição austríaca da literatura auto-reflexiva e reveladora da crise na linguagem que Hugo von Hofmannstahl descreveu, em 1902, em Carta a Lord Chandos.

A obra de Thomas Bernhard é, pois, visivelmente devedora da cultura e da lingua com que se digladia, o

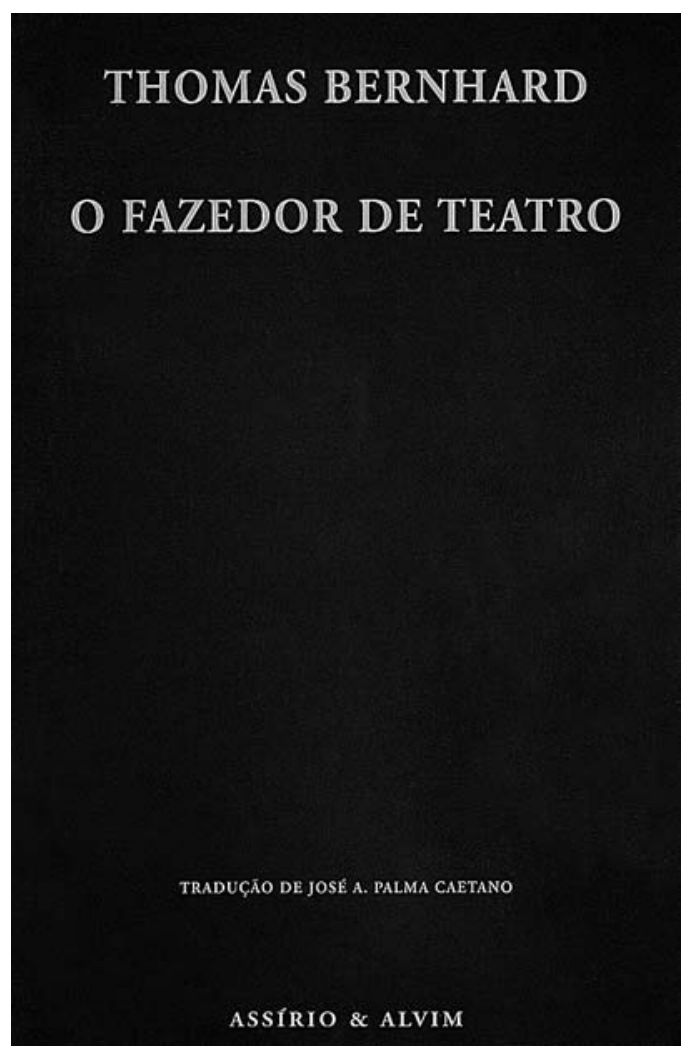

que, a um tempo, a torna singular e "potencialmente" intraduzivel.

2. Os fazedores de tradução: Da paixão pelo texto à necessidade de comunicar

É evidente que uma tradução vive entre o possivel e o impossivel e por isso nada é mais vulnerável e exposto.

A vulnerabilidade parece habitar sempre o impulso tradutório, situado que está entre a necessidade e o horizonte utópico. Dai que a primeira questão que se põe a um tradutor -

"qualquer" tradutor - será sempre a de saber como transmitir a paixão por um texto numa língua e cultura outras: questão necessariamente reiterada diante de cada obra a suscitar resposta(s) irremediavelmente singular(es). Porque um texto é sempre irrepetível. Porque "[c]ada tradução é, em certa medida, uma invenção, constituindo por isso um texto único" (Paz 1971: 13, tradução minha). No caso d'O fazedor de teatro, existem duas inescapáveis considerações preliminares à tradução: 


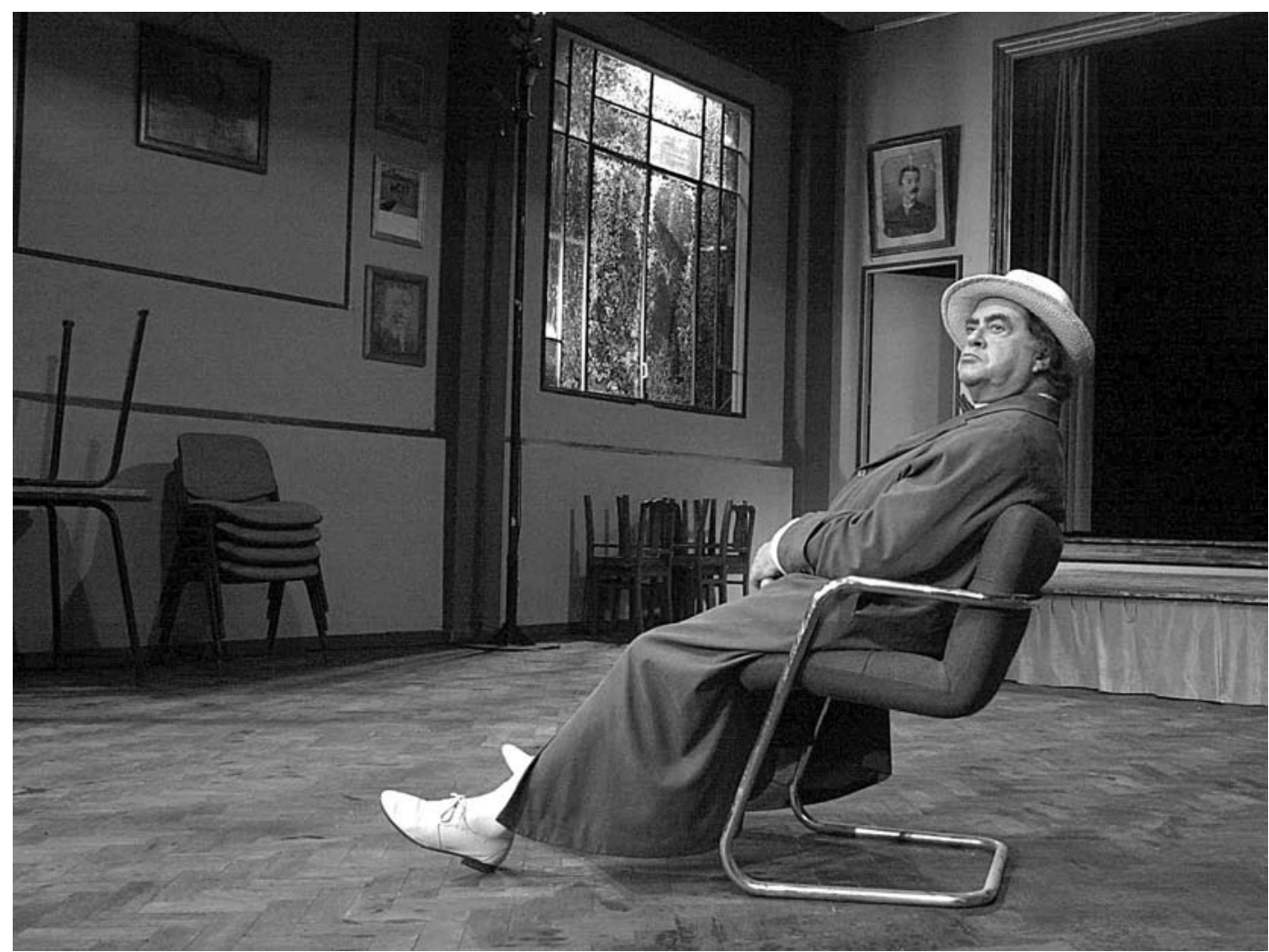

(i) 0 facto de este texto poder funcionar como texto dramático' - a ser publicado e lido - e/ou como texto teatral - a ser visto num espaço e tempo circunscritos - é, para a tradução, uma questão fundamental, pois a prioridade cronológica de um ou de outro determinará inequivocamente as escolhas do tradutor. Assim, num texto dramático, 0 impulso estrangeirante será sempre menos arriscado do que num texto espectacular, uma vez que o tradutor disporá, pelo menos teoricamente, de um espaço paratextual em que justificar / explicar as suas opções e o leitor poderá recuperar entendimentos diversos da peça.

Num texto teatral, a opção por um léxico mais exigente e uma sintaxe menos linear - características comuns ao esforço literalizante - é potencialmente mais desequilibrante, dependendo a sua aceitação do risco de incomunicabilidade que encenador e actores estão dispostos a correr e da avaliação da enciclopédia e disponibilidade intelectual do público-alvo.

(ii) A presença da Áustria na peça, enquanto tema presente na toponímia, gastronomia, história, etc. - e dialecto regional, individualiza o texto adentro de um contexto específico que poderá ser preservado ou anulado pela tradução, através de estratégias de pendor exoticizante ou domesticador.

É evidente que estas duas considerações prévias se entrecruzam numa rede de potencialidades interpretativas que gerará o texto traduzido.

\section{3. $O$ fazedor de teatro: Bernhard em português}

Traduzir para pôr em cena, isto é - procurar transcrever a exacta actuação do autor, que não escreveu para compêndios mas para as tábuas de um palco.

António Pedro

José A. Palma Caetano (n. 1931) tem vindo, nos últimos tempos, a traduzir uma mão-cheia de obras do autor austriaco que nos ocupa, entre as quais se contam 0 sobrinho de Wittgenstein: Uma amizade (2000), Na terra e no inferno (2001), Antigos mestres (2003) e, mais recentemente, Extinção $(2004)^{2}$.

O fazedor de teatro (2004) é assim a primeira obra dramatúrgica que Palma Caetano traduz. As caracteristicas do género, aliadas à provocação ao público subjacente a
0 fazedor de teatro,

de Thomas Bernhard, enc. Joaquim Benite, Companhia de Teatro de Almada, 2004 (Morais e Castro), fot. Humberto Sousa.

2 Além de Bernhard, Palma Caetano traduziu outros autores austríacos, como Heimito von Doderer (A flagelação das bolsinhas de camurça / Um outro Kratki Baschik, 2004), Hugo von Hofmannsthal (O livro dos amigos, 2002) e Peter Handke (Poema à duração, 2002).

${ }^{3}$ Uma nota curiosa: a opção por se concentrar, enquanto tradutor

literário, numa região da Europa, a Áustria, não se alia neste tradutor a uma especialização num género determinado opção mais corrente em tradução -, tendo Palma Caetano traduzido narrativa, lirica e, com o fazedor de teatro, também drama. 
este texto, constituem talvez as maiores dificuldades que se colocam ao tradutor, porquanto aquelas como esta parecem promover uma tradução fluente e desprovida de efeitos estrangeirantes que tendencialmente afastam o leitor / espectador do texto, ao provocarem um efeito de estranhamento. Acresce a estes vectores de comunicabilidade o facto d'O fazedor de teatro ser, para todos os efeitos (dramatúrgicos e tradutórios), um (quase) monólogo, em que Bruscon, o protagonista, chegado a Utzbach, uma cidadezinha de provincia, reflecte sobre as relações entre teatro e mundo. Esta reflexão, de que está ausente qualquer sinal de pontuação, a recordar estratégias joyceanas, parece igualmente pressupor uma estratégia de transparência discursiva (cf. Venuti 1992).

Por outro lado, porém, tanto o monólogo de Bruscon como a situação dramatúrgica remetem constantemente para o caso austríaco. Na verdade, as referências toponímicas, históricas e gastronómicas abundam, colorindo inegavelmente o tecido textual da cultura em que aquele se insere. Ora, esta especificidade exigiria preferencialmente uma estratégia de resistência (cf. ibidem) em relação à língua de chegada. A ser assim, 0 fazedor de teatro reclamaria estratégias tradutórias potencialmente antagónicas e irreconciliáveis. Cabe ao tradutor decidir qual dos efeitos do texto é prioritário no contexto próprio da tradução.

A julgar pelo texto traduzido, Palma Caetano permanece, de certo modo, refém de dois impulsos, por vezes, contraditórios. De um lado, o desejo de fazer justiça às idiossincrasias estético-culturais da peça, a revelar-se sobretudo no cultivo de um algum exotismo lexical "actor nacional" (p. 11), "encomendar simplesmente sopa de massa frita" (p. 41), "sopa com almôndegas de fígado" (p. 44), "massa com salada de carne" (p. 85), "a que deu à luz" (p. 93), sendo o contorcionismo léxico-morfosintáctico que ocorre com "os intérpretes femininos" (pp. 31-32) o exemplo mais evidente de uma vontade de fazer jus ao traço textual - e de uma sintaxe ocasionalmente pouca fluida porque orientada para a construção alemã : "Desprezo total reciproco" (p. 26), "tudo junto é um único absurdo" (p. 34), "Geralmente como até de olhos fechados a minha sopa de massa frita" (p. 45), "Estão todas estragadas as cortinas" (p. 51). Especialmente complexa é a tradução de construções participiais alemãs - "a mulher sentindo-se permanentemente desconsiderada e fazendome doido" (p. 48) ou "0 hospedeiro que vem disfarçadamente por assim dizer" (p. 125) - e das nominalizações de verbos e adjectivos.

Por outro lado, verifica-se na tradução a vontade de produzir um texto que espelhe o que na peça é "potencialmente" universal porque atinente à condição humana. Os aspectos mais evidentes deste impeto de comunicabilidade são (i) as pequenas incisões no texto (vide redução na p. 28 e corte na p. 85, explicáveis pela irredutibilidade linguística à tradução, e as reduções menos claras nas pp. 55 e 56) e (ii) o recurso pontual a um vocabulário marcadamente naturalizante - "mini-freguesia" (p. 13), "meu caro senhor" (pp. 15, 25), com a inclusão de "caro" em nome da fluência, "diga-Ihe lá" (p. 27), "coisas do arco-da-velha" (p. 45), etc.

Globalmente, pode então dizer-se que 0 fazedor de teatro é uma tradução que tende a ficar "rente ao texto" de partida, no dizer feliz de Sophia de Mello Breyner. Se, como escreveu em 1758 Jean d'Alembert (1758), "[o] que mata uma tradução não são os erros, é a frieza" (apud Barrento 2002: 261), então esta é uma tradução bem viva porque nela pulsa uma enorme paixão pela escrita de Thomas Bernhard.

\section{Referências bibliográficas}

AGUIAR E SILVA, Vitor Manuel (1983), Teoria da literatura, Coimbra, Almedina.

BARRENTO, João (2002), "Traduções, seduções, paixões", in O poço de Babel: Para uma poética da tradução literária, Lisboa, Relógio d'Água, pp. 260-62.

HÖLLER, Hans (1993), Thomas Bernhard, Reinbeck bei Hamburg, Rowohlt. JAKOBSON, Roman (2000), "On Linguistic Aspects of Translation", in

Lawrence Venuti (ed.), The Translation Studies Reader, London \& New York, Routledge.

PAZ, Octavio (1971), Traducción: Literatura y literalidad, Barcelona, Tusquets. VENUTI, Lawrence (ed.) (1992), Rethinking Translation: Discourse, Politics, Subjectivity, London \&t New York, Routledge. 